\title{
Comparative Analyses of Microalgal Lipid Yield in Different Cultivation Systems
}

\author{
Suchitra Rakesh", S. Poonguzhali, B. Saranya and K. Jothibasu \\ Thanthai Roever Institute of Agriculture and Rural Development, \\ Perambalur - 621 115, Tamil Nadu, India \\ *Corresponding author
}

A B S T R A C T

Keywords

Microalgae,

Photobioreactor,

Raceway, Biomass,

Fatty acid methyl

ester, Biofuel.

Article Info

Accepted:

28 August 2017

Available Online:

10 September 2017
An analysis of fatty acid profile for production of biomass using the oil-rich microalgae Botryococcus sp. MCC30 and Chlorella sorokiniana MIC-G5 was performed, which included Flask cultivation, raceway pond and photobioreactor for microalgal cultivation. Both the cultures were grown for 33 days in different growth systems and were evaluated for growth daily. The results showed that in both the microalgal cultures, raceway pond has not only shown maximum biomass yield but also accounts for maximum fatty acid methyl esters, and thus raceway system of mass cultivation considered economically feasible for biofuel production.

\section{Introduction}

Microalgal biomass is one of the most promising sources of energy since it is renewable and neutral with respect to carbon dioxide emissions. Microalgae use solar energy to covert carbon dioxide into carbohydrates, lipids and proteins, with higher areal efficiency than land plants. Microalgal biomass contains approximately 50 per cent carbon by dry weight (Sanchez et al., 2003). For large-scale production of microalgae, algal cells are continuously mixed to prevent the algal biomass from settling (Molina et al., 1999) and nutrients are provided during daylight hours, when the algae are reproducing. However, up to one quarter or the algal biomass produced during the day can be lost due to respiration during the night
(Chisti, 2007). Closed photobioreactors have attracted much interest because they allow a better control of the cultivation conditions than open systems. With closed photobioreactors, higher biomass productivities are obtained and contamination can be easily prevented (Molina et al., 2000). Higher bioreactor costs are therefore compensated for by higher productivity as recent studies show (Chisti, 2007). The biomass productivity of photobioreactors can be 13 times more than that of a traditional raceway pond on average (Chisti, 2007).

Cultivation of algae in open ponds has been extensively studied in the past few years (Tredici and Materassi, 1992; Hase et al., 
2000). The most commonly used systems include shallow big ponds, tanks, circular ponds and raceway ponds. One of the major advantages of open ponds is that they are easier to construct and operate than most closed systems. However, major limitations in open ponds include poor light utilization by the cells, evaporative losses, diffusion of carbon dioxide to the atmosphere, and requirement of large areas of land. Furthermore, contamination by predators and other fast growing heterotrophs have restricted the commercial production of algae in open culture systems to only those organisms that can grow under extreme conditions. From the aquatic species program collection of over 3,000 photosynthetic organisms, none were found to be able to continually dominate an open pond and have desirable bio fuel properties (Sheehan et al., 1998). Hence, the objective of this work is to perform comparative analyses of biomass production and lipid yield using both raceway ponds and photobioreactor system.

\section{Materials and Methods}

\section{Microalgae and their growth conditions}

Botryococcus sp. MCC30 and Chlorella sorokiniana MIC-G5 were obtained from culture collection of Division of Microbiology and CCUBGA, IARI, New Delhi. These cultures were grown in trays under greenhouse conditions of $25^{\circ} \mathrm{C}$ temperature and natural sunlight $(60.8-67.5 \mu \mathrm{mol}$ photons $\mathrm{m}^{-2} \mathrm{~s}^{-1}$ ) in formulated commercial medium containing NPK fertilizers (i.e., Urea, single super phosphate and muriate of potash) in appropriate amounts. Batch cultures were maintained by inoculating a known volume of fresh medium every two weeks for use as seed culture. The biomass of cultured cells was harvested after $7^{\text {th }}$ day by centrifugation and the wet cell mass was dried and used for analyses.
Mass multiplication of microalgae in photobioreactor

Botryococcus sp. and Chlorella sorokiniana were operated for three weeks in photobioreactor. Initial inoculums of $0.5 \mathrm{~g}$ of respective culture was used and inoculated in 4 liter of BG-11 broth. Daily optical density was estimated by spectrophotometer for 34 day. After $34^{\text {th }}$ day, total biomass and lipid were separately estimated for both the cultures.

\section{Mass multiplication of microalgae in raceway}

Botryococcus sp. and Chlorella sorokiniana were grown in raceway system for three weeks with initial inoculums of $0.5 \mathrm{~g}$ each and inoculated in 1000 liter of commercial medium. Daily optical density (at $620 \mathrm{~nm}$ ) and biomass was estimated. After $34^{\text {th }}$ day, total biomass and lipid were also estimated separately for both the cultures.

\section{Biomass estimation by gravimetric method}

The biomass was harvested from the culture broth by centrifugation at 4,000 rpm (20 min, $4^{\circ} \mathrm{C}$ ) and the microalgal biomass was placed in a pre-weighed watch glass. The biomass was dried in an oven at $60^{\circ} \mathrm{C}$ for $12 \mathrm{~h}$. the watch glass with the biomass was weighed and the net mass of the microalgal cells was determined by subtracting the final weight from weight of the watch glass (Mutanda et al., 2011).

\section{GC-MS analysis}

The algal oil extraction procedure was adopted from the protocol described by Bligh and Dyer (1959). The amount of total fatty acids (sum of free and bounded fatty acids) was obtained by transesterification into the corresponding methyl esters (Fatty Acid 
Methyl Esters). The extract was refluxed for 10 min with $4 \mathrm{~mL}$ methanolic $\mathrm{NaOH} 0.5 \mathrm{M}$, then $5 \mathrm{~mL}$ of $\mathrm{MeOH} / \mathrm{BF}_{3}$ was added and the mixture refluxed for $2 \mathrm{~min}$ followed by the addition of $10 \mathrm{~mL}$ of $n$-hexane. After cooling, saturated $\mathrm{NaCl}$ aqueous solution was added with stirring, followed by the separation of hexane layer containing FAMEs, which were dried over anhydrous sodium sulphate and dilutedprior to GC-MS analysis (Fabbri et al., 2005). FAME analyses were performed both the microalgal cultures using a 6850 Agilent HP gas chromatograph connected to a 5975 Agilent HP quadrupole mass spectrometer. Analytes were separated by a HP-5 fusedsilica capillary column (stationary phase poly [5\% diphenyl/95\% dimethyl]-siloxane, $30 \mathrm{~m}$, $0.25 \mathrm{~mm}$ i.d., $0.25 \mathrm{~mm}$ film thickness) using helium as carrier gas (at constant pressure, 33 $\mathrm{cm} \mathrm{s}^{-1}$ linear velocity at $200^{\circ} \mathrm{C}$ ). Measurement solutions were injected under splitless condition with injector temperature set at $280^{\circ} \mathrm{C}$. Mass spectra were recorded under electron ionization $(70 \mathrm{eV})$ at a frequency of 1 scan $\mathrm{s}^{-1}$ within the $12-450 \mathrm{~m} / \mathrm{z}$ range. The following thermal program was used: $130^{\circ} \mathrm{C}$ for $3 \mathrm{~min}$, then $10^{\circ} \mathrm{C} / \mathrm{min}$ up to $300^{\circ} \mathrm{C}$ and hold for $10 \mathrm{~min}$. The quantity of extracted compounds was reported as percentage yields of the extracted algal biomass (Samori et al., 2010).

\section{Statistical analysis}

The extracted lipid contents from the four microalgal species were compared according to the five disruption methods using a oneway ANOVA. The level of significant difference was $\mathrm{P}<0.05$.

\section{Results and Discussion}

\section{Microalgal biomass production}

Conventional open pond algal production systems are age old systems for biomass production. Recently closed photobioreactors have been developed for continuous and increased biomass production. In the present investigation, microalgae i.e., Botryococcus sp. MCC30 and Chlorella sorokiniana MICG5 were grown in different growth systems viz., outdoor raceway ponds, flask culture and photobioreactor. A shown in figure, the cell growth reached maximum after $24^{\text {th }}$ and $20^{\text {th }}$ day (for Botryococcus sp. MCC30 and Chlorella sorokiniana MIC-G5) in $5 \mathrm{~L}$ photobioreactor, then decreased gradually in the subsequent days. However, growth under outdoor raceway pond was comparatively higher than the rest of the two systems. The vast bulk of microalgae cultivated today are grown in open ponds. Open ponds can be built and operated very economically and hence offer many advantages as long as the species for cultivation can be maintained (Weissman et al., 1988). Raceways are perceived to be less expensive than photobioreactors, because they cost less to build and operate. Economically, open pond system of biomass production is 10 times less costly in comparison to photobioreactor (Sheehan et al., 1998). In present study, compared to all the growth systems, outdoor raceways pond has given maximum biomass in both the cultures as shown in figure 1 .

\section{Characterization of algal lipid for biodiesel production}

The fatty acid compositions of microalgae oil may vary to individual species/strains and their environmental conditions. Algal oils contain a high degree of polyunsaturated fatty acids with four or more double bonds when compared to vegetable oils (Zittelli et al., 2006; Rodolfi et al., 2009). The identification of lipid composition in selected algal strain is essential for determining the suitability to biodiesel and fuel quality. Hence, characterizing the algal lipid for biodiesel production was studied. 
Table.1 Details of FAME profiles generated in the microalgae grown in raceway and flask culture system

\begin{tabular}{|c|c|c|c|c|}
\hline \multirow{3}{*}{ Fatty acids } & \multicolumn{4}{|c|}{ Relative per cent of fatty acids } \\
\hline & \multicolumn{2}{|c|}{ Raceway pond } & \multicolumn{2}{|c|}{ Flask culture } \\
\hline & $\begin{array}{c}\text { Botryococcus sp. } \\
\text { MCC } 30\end{array}$ & $\begin{array}{c}\text { Chlorella sorokiniana } \\
\text { MIC-G5 }\end{array}$ & $\begin{array}{c}\text { Botryococcus sp. } \\
\text { MCC } 30\end{array}$ & $\begin{array}{c}\text { Chlorella sorokiniana } \\
\text { MIC-G5 }\end{array}$ \\
\hline Methyl tetradecanoate (C14:0) & 0.87 & 1.10 & - & - \\
\hline $\begin{array}{l}\text { Pentadecanoic acid, methyl ester } \\
\text { (C15:0) }\end{array}$ & 1.78 & 2.76 & - & 8.27 \\
\hline $\begin{array}{l}\text { Hexadecanoic acid, methyl ester } \\
\text { (C16:0) }\end{array}$ & 38.66 & 35.32 & 14.00 & - \\
\hline $\begin{array}{l}\text { 9-Hexadecenoic acid, methyl ester, (Z)- } \\
\text { (C16:1) }\end{array}$ & 5.94 & 10.58 & 3.72 & - \\
\hline $\begin{array}{l}\text { 7,10-Hexadecadienoic acid, methyl } \\
\text { ester (C16:2) }\end{array}$ & 3.25 & 1.72 & - & - \\
\hline $\begin{array}{l}\text { Methyl 4,7,10,13-hexadecatetraenoate } \\
\text { (C16:4) }\end{array}$ & - & 2.21 & - & - \\
\hline $\begin{array}{l}\text { Heptadecanoic acid, methyl ester } \\
\text { (C17:0) }\end{array}$ & 0.15 & 3.96 & - & - \\
\hline $\begin{array}{l}\text { Cyclopropaneoctanoic acid, 2-hexyl-, } \\
\text { methyl ester (C17:2) }\end{array}$ & 1.62 & 0.35 & - & - \\
\hline $\begin{array}{l}\text { Octadecanoic acid, methyl ester } \\
\text { (C18:0) }\end{array}$ & 4.01 & 3.22 & 1.55 & 5.26 \\
\hline $\begin{array}{l}\text { 11-Octadecenoic acid, methyl ester, } \\
\text { (Z)- (C18:1) }\end{array}$ & 4.40 & 18.68 & 7.80 & 3.87 \\
\hline $\begin{array}{l}\text { 9,12-Octadecadienoic acid, methyl ester } \\
\text { (C18:2) }\end{array}$ & 11.51 & 11.27 & 2.44 & 4.02 \\
\hline $\begin{array}{l}\text { 9,12,15-Octadecatrienoic acid, methyl } \\
\text { ester, (Z,Z,Z)- (C18:3) }\end{array}$ & 15.30 & 0.45 & - & - \\
\hline $\begin{array}{l}\text { Nonadecanoic acid, methyl ester } \\
\text { (C19:0)- }\end{array}$ & - & 0.12 & - & - \\
\hline Eicosanoic acid, methyl ester (C20:0) & - & 0.16 & - & - \\
\hline Total FAMEs & 87.49 & 91.90 & 29.51 & 21.42 \\
\hline
\end{tabular}


Fig.1 Biomass produced by microalgae generated in different culture systems

a. Botryococcus sp. MCC30

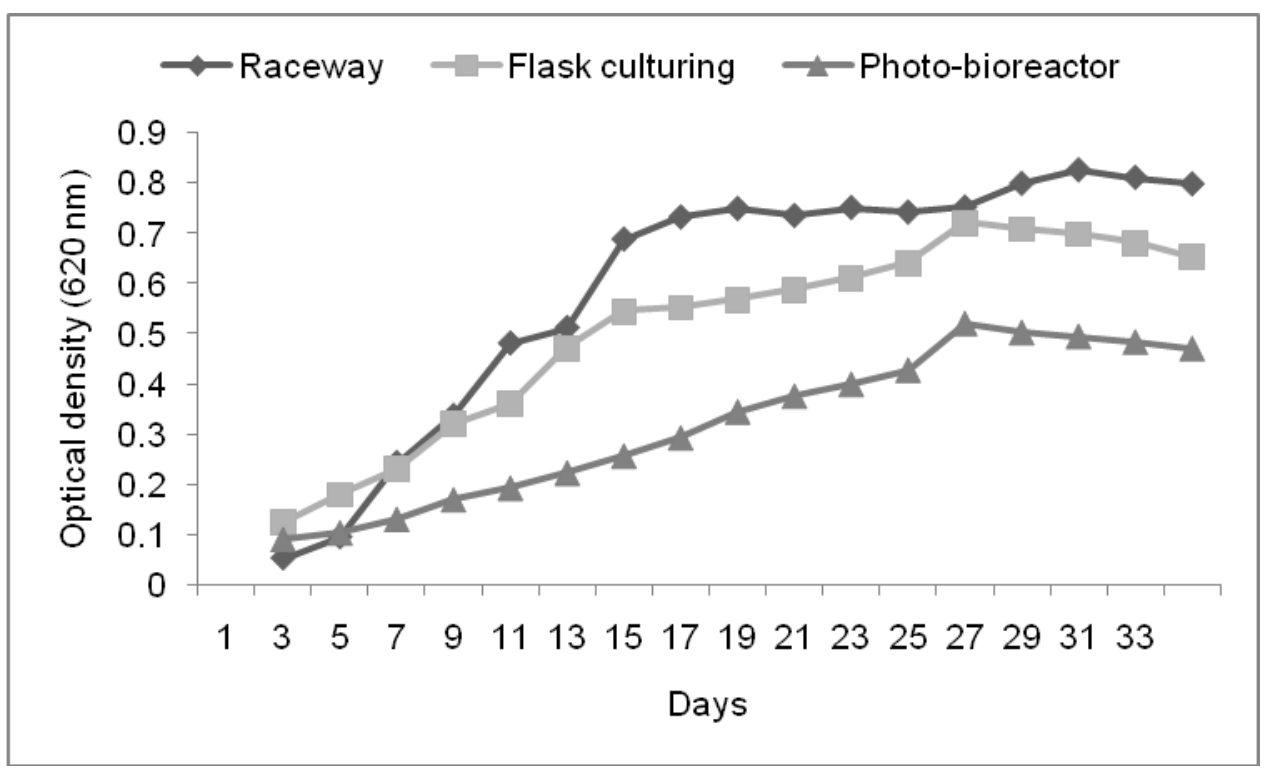

b. $\quad$ Chlorella sorokiniana MIC-G5

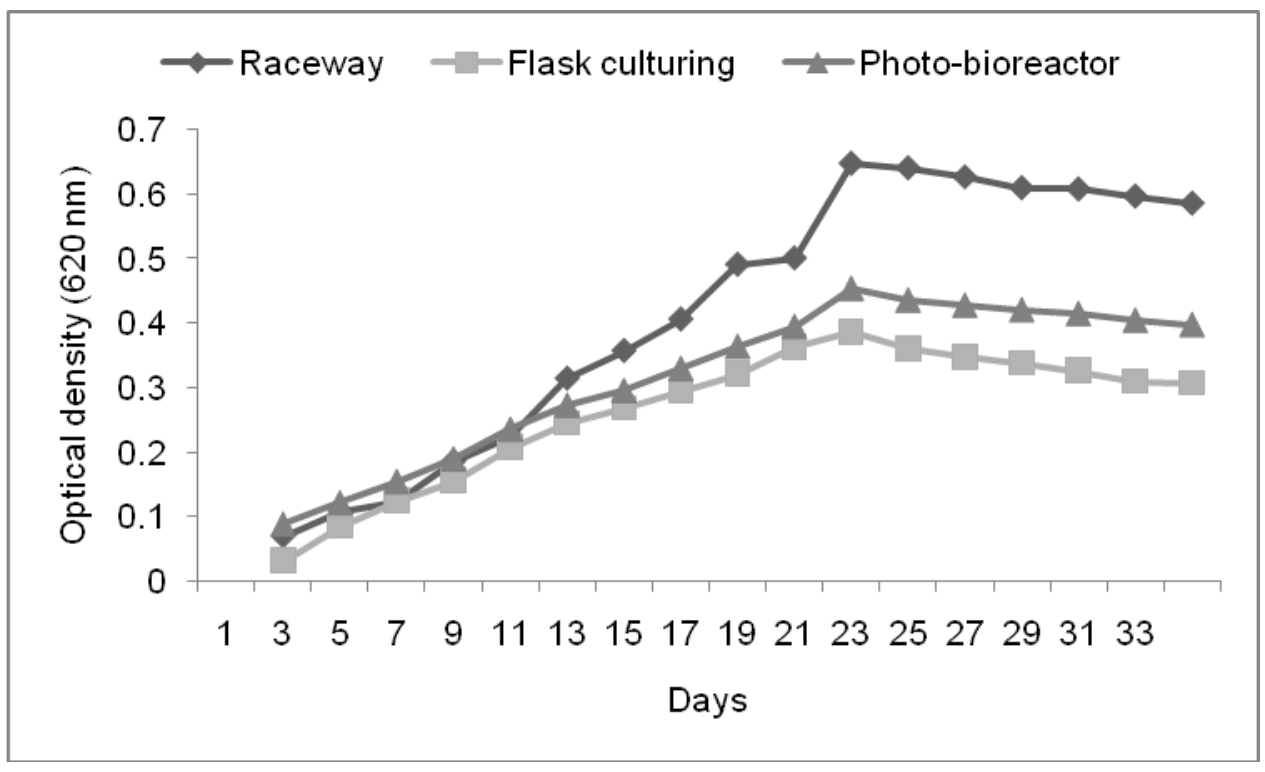

It is well known that some green microalgae can accumulate very large amounts of triacylglycerols in the stationary phase of the growth (Thompson, 1996), if cell division is inhibited due to nutrient depletion, especially nitrogen. These triacylglycerol fatty acids are principally C16:0 and C18:1 (Thompson,
1996). In the present study, the total lipid from both the algal cultures was extracted according to the method of Bligh and Dyer (1959) and total lipids were measured gravimetrically and expressed as dry weight percentage. With respect to performance in different growth systems, both the microalgae 
has shown better lipid yield under raceway multiplication. The fatty acid methyl esters (FAMEs) of the biodiesel from both the algal cultures are presented in table 1 . The profile showed the presence of the following fatty acids: 14:0, 15:0, 16:0, 16:1, 16:2, 16:4, 17:0, $17: 2,18: 0,18: 1,18: 2,18: 3,19: 0$ and 20:0. However, the dominant fatty acids were $16: 0$, 16:1, 18:1, 18:2 and 18:3.

Under raceway, eleven FAMEs derivatized in the biodiesel from Botryococcus sp. MCC30, and the most abundant composition was hexadecanoic acid methyl ester with the content of $38.66 \%$. Octadecanoic acid methyl ester, octadecenoic acid methyl ester, octadecadienoic acid methyl ester and octadecatrienoic acid methyl ester are 18 carbon acid methyl esters, and the total content of these four FAMEs was over $35.22 \%$. While in Chlorella sorokiniana MIC-G5, total 16 carbon acid methyl esters content was around 49.77\%; however, total FAMEs content of 18 carbon acid methyl esters was over $33.62 \%$. This resulted in the high quality of the biodiesel. However, fatty acid methyl esters were $29.51 \%$ in Botryococcus sp. MCC 30 , and $21.42 \%$ in Chlorella sorokiniana MIC-G5, when grown in flask culture system. This is in agreement with the findings of Dayananda et al., (2005). $\mathrm{Xu}$ et al., (2006) identified fatty acid methyl esters in Chlorella protothecoides biodiesel viz., 9, 12-octadecadienoic acid methyl ester (C18:2),

9-octadecenoic acid methyl ester (C18:0), hexadecanoic acid methyl ester (C16:0) as their major fatty acid methyl esters based on their relative content. Similar fatty acid methyl esters were noticed in the present study, which confirmed the feasibility and high quality biodiesel from both the microalgal cultures.

Botryococcus braunii is a colonial green alga, in which cells associate via a complex extracellular matrix (ECM), and the colonies are enclosed in a retaining wall festooned with a fibrillar sheath dominated by arabinose-galactose polysaccharides, which sequesters ECM liquid hydrocarbons. The cells produce prodigious amounts of liquid hydrocarbons, hence are of significance to biofuel researchers as that can be readily converted into conventional combustion engine fuels (Weiss et al., 2012). In a previous study (Knothe, 2008), palmitic, stearic, oleic (C18:1) and linoleic acid (C18:2) were recognized as the most common fatty acids contained in biodiesel. The cell wall of Chlorella sorokiniana is known to contain $68 \%$ carbohydrates and $17 \%$ proteins, with major monosaccharides as rhamnose, glucuronic acid, galactose, xylitol and mannose, with the latter proving to be a major factor in contributing to its resistance to acetolysis and cell breakage. Further, vegetative walls contain a microfibrillar material composed predominantly of glucose and presumed to be cellulose. In particular, oils with high oleic acid content have been reported to have a reasonable balance of fuel properties (Rashid et al., 2008). The properties of a biodiesel fuel, including its ignition quality, combustion heat, cold filter plugging pint (CFPP), oxidative stability, lubricity and viscosity are determined by the structure of its component fatty esters. As such, higher oleic acid content increases the oxidative stability for longer storage (Knothe, 2005) and decreases the CFPP for use in cold regions (Stournas et al., 1995). Therefore, both the tested microalgal cultures showed the highest oleic acid content, making it the most suitable for production of good quality biodiesel.

Biodiesel production from microalgae is a goal that still needs much research. All the three microalgal growth systems i.e., flask culture, raceway pond and photobioreactor has showed good growth in this study, 
however raceway pond has performed comparatively better in terms of biomass yield and total content of fatty acid methyl esters, and is thus considered economically feasible for mass cultivation of both the microalgal culture for the purpose of biofuel generation.

\section{References}

Bligh, E.G., and W.J. Dyer. 1959. A rapid method of total lipid extraction and purification. Can. J. Biochem. Physiol., 37: 911-917.

Chisti, Y., 2007. Biodiesel from microalgae. Biotechnol. Adv., 25: $\quad 294$ 306.Dayananda, C., R. Sarada, S. Bhattacharya and G.A. Ravishankar. 2005. Effect of media and culture conditions on growth and hydrocarbon production by Botryococcus braunii. Process Biochem., 40: 3125-3131.

Fabbri, D., V. Baravelli, G. Chiavari and S. Prati. 2005. Profiling fatty acids in vegetable oils by reactive pyrolysis-gas chromatography with dimethyl carbonate and titanium silicate. J. Chromatogr. A., 110: 218-222.

Hase, R., Oikawa H, Sasso C, Morito M, Watabe Y (2000) Photosynthetic production of microalgal biomass in a race way system under greenhouse conditions in Sendi City. J Biosci Bioeng., 89:157-163.

Knothe, G., 2005. Dependence of biodiesel fuel properties on the structure of fatty acid alkyl esters. Fuel Process. Technol., 86: 1059-1070.

Knothe, G., $2008 . \quad$ "Designer" biodiesel:optimizing fatty ester composition to improve fuel properties. Energy Fuel, 22: 1358-1364.

Molina, G.E., G.A. Fernandez, C.F. Garcia and Y. Chisti. 1999. Photobioreactors: light regime, mass transfer, and scaleup. J. Biotechnol., 70: 231-247.
Molina, G.E., G.A. Fernandez, F.C. Camacho, F.C. Rubio and Y. Chisti. 2000. Photobioreactors: light regime, mass transfer, and scaleup. J. Biotechnol., 70: 231-247.

Mutanda, T., S. Karthikeyan and F. Bux. 2011. The utilization of post-chlorinated municipal domestic wastewater for biomass and lipid production by Chlorella spp. Under batch conditions. Appl. Biochem. Biotechnol., 164: 11261138.

Rashid, M.M., J.K.G. Kramer, M.A. Wood and B.W. McBride. 2008. Supplemental algal meal alters the ruminal trans-18:1 fatty acid and conjugated linoleic acid composition in cattle1. Journal of Animal Science, 86(1): 187-196.

Rodolfi, L., Z.G. Chini, N. Bassi, G. Padovani, N. Biondi, G. Bonini and M.R. Tredici. 2009. Microalgae for oil: strain selection, induction of lipid synthesis and outdoor mass cultivation in a low-cost photobioreactor. Biotechnol. Bioeng., 102: 100-112.

Samori, C., C. Torri, G. Samori, D. Fabbri, P. Galletti, F. Guerrini, R. Pistocchi and E. Tagliavini. 2010. Extraction of hydrocarbons from microalga Botryococcus braunii with switchable solvents. Biores. Technol., 101: 32743279.

Sanchez, M. A., M.C. C.Garcia, A.C. Gomez, F.G. Camacho, M. Grima and Y. Chisti. 2003. Shear stress tolerance and biochemical characterization of Phaeodactylum tricornutum in quasi steady-state continuous culture in outdoor photobioreactors. Biochem. Eng. J., 16: 287-297.

Sheehan, J., T. Dunahay, J. Benemann and P. Roessler. 1998. A look back at the US Department of Energy's aquatic species program - Biodiesel from Algae. ReportNREL/TP-580-24190. National Renewable Energy Laboratory, Golden, 
$\mathrm{CO}$.

Stournas, S., E. Lois and A. Serdari. 1995. Effect of fatty acid derivatives on the ignition quality and cold flow of diesel fuel. J. Am. Oil Chem. Soc., 72(4): 433437.

Thompson, G.A., 1996. Lipids and membrane function in green algae. Biochimica ET Biophysica Acta 1302: 17-45.

Tredici, M.R., and R. Materassi, 1992. From open ponds to vertical alveolar panels: the Italian experience in the development of reactors for the mass cultivation of phototrophic microorganisms. Journal of Applied Phycology, 4(3): 221-231.

Weiss, T.L., R. Roth, C. Goodson, S. Vitha, I, Black, P. Azadi, J. Rusch, A. Holzenburg, T.P. Devarenne and U. Goodenough. 2012. Colony organization in the green alga
Botryococcus braunii (race B) is specified by a complex extracellular matrix. Eukaryotic Cell, 11(12): 14241440.

Weissman, J.C., R.P. Goebel and J.R. Benemann. 1988. Photobioreactor design: mixing, carbon utilization and oxygen accumulation. Biotechnol. Bioeng, 31: 336-344.

Xu, H., X.L. Miao and Q.Y. Wu. 2006. High quality biodiesel production from a microalga Chlorella protothecoides by heterotrophic growth in fermenters. $J$. Biotechnol., 126: 499-507.

Zittelli, G.C., L. Rodolfo, N. Biondi and M.R. Tredici. 2006. Productivity and photosynthetic efficiency of outdoor cultures of Tetraselmis suecica in annular columns. Aquaculture, 261: 932-943.

\section{How to cite this article:}

Suchitra Rakesh, S. Poonguzhali, B. Saranya and Jothibasu, K. 2017. Comparative Analyses of Microalgal Lipid Yield in Different Cultivation Systems. Int.J.Curr.Microbiol.App.Sci. 6(9): 3218-3225. doi: https://doi.org/10.20546/ijcmas.2017.609.396 